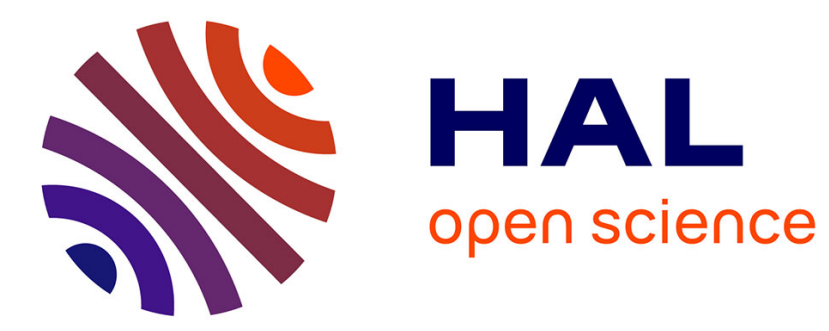

\title{
Infrared Thermography applied to measurement of Heat transfer coefficient of water in a pipe heated by Joule effect
}

\author{
P. Leblay, J.F. Henry, D. Caron, D. Leducq, A. Bontemps, L. Fournaison
}

\section{> To cite this version:}

P. Leblay, J.F. Henry, D. Caron, D. Leducq, A. Bontemps, et al.. Infrared Thermography applied to measurement of Heat transfer coefficient of water in a pipe heated by Joule effect. QIRT - 11th Quantitative InfraRed Thermography, Jun 2012, Naples, Italy. 10 p. hal-00765917

\section{HAL Id: hal-00765917 \\ https://hal.science/hal-00765917}

Submitted on 17 Dec 2012

HAL is a multi-disciplinary open access archive for the deposit and dissemination of scientific research documents, whether they are published or not. The documents may come from teaching and research institutions in France or abroad, or from public or private research centers.
L'archive ouverte pluridisciplinaire HAL, est destinée au dépôt et à la diffusion de documents scientifiques de niveau recherche, publiés ou non, émanant des établissements d'enseignement et de recherche français ou étrangers, des laboratoires publics ou privés. 


\title{
Infrared Thermography applied to measurement of Heat transfer coefficient of water in a pipe heated by Joule effect
}

\author{
by P. Leblay ${ }^{\star}$, J.-F. Henry**, D. Caron**, D. Leducq ${ }^{\star}$, A. Bontemps ${ }^{\star \star \star}$ and L. Fournaison*
}

*LGP2ES Irstea-GPAN, 1, rue Pierre-Gilles de Gennes, CS 10030, 92761 Antony Cedex, France, patrick.leblay@irstea.fr

**University of Reims Champagne-Ardenne, URCA/GRESPI/Thermomécanique, UFR Sciences, 51687 Reims Cedex 2, jf.henry@univ-reims.fr

${ }^{* * *}$ CEA Greth, 17, rue des Martyrs, 38054, Grenoble, France, andre.bontemps@cea.fr

\begin{abstract}
A methodology has been developed based on periodic excitation by Joule effect and infrared thermography measurement. It has been applied to measure heat transfer coefficients of water flowing in a round tube and in a multiport-flat tube. Models were developed to deduce heat transfer coefficient from wall temperature amplitude and heat flux measurement. For the round tube and for the multiport flat tubes, Reynolds number investigated ranges respectively from 2000 to 14000 and from 800 to 10000 and heat flux from $5 \mathrm{~W}$ to $29 \mathrm{~W}$ and from $10 \mathrm{~W}$ to $70 \mathrm{~W}$. The good agreement between experimental and theoretical results has demonstrated the reliability of the methodology. This methodology also present the advantage to require a low heat flux, is not intrusive and fluid independant.
\end{abstract}

Table 1. Nomenclature

\begin{tabular}{|c|c|c|c|}
\hline$a$ & thermal diffusivity $a=k /\left(\rho c_{p}\right)\left(\mathrm{m}^{2} \cdot \mathrm{s}^{-1}\right)$ & $V$ & volume $\left(\mathrm{m}^{3}\right)$ \\
\hline$c_{p}$ & specific heat capacity $\left(\mathrm{J} \cdot \mathrm{kg}^{-1} \cdot \mathrm{K}^{-1}\right)$ & $v$ & mean velocity $\left(\mathrm{m} \cdot \mathrm{s}^{-1}\right)$ \\
\hline$D$ & diameter $(\mathrm{m})$ & $\varepsilon$ & minimazation criterion (-) \\
\hline$D_{h}$ & hydraulic diameter (m) & $\theta$ & reduced temperature $(\mathrm{K})$ \\
\hline$f$ & frequency $\left(s^{-1}\right)$ & $\Lambda$ & Darcy coefficient (-) \\
\hline$h$ & heat transfer coefficient $\left(\mathrm{W} \cdot \mathrm{m}^{-2} \cdot \mathrm{K}^{-1}\right)$ & $\mu$ & dynamic viscosity (Pa.s) \\
\hline$j$ & imaginary number such as $j^{2}=-1(-)$ & $\rho$ & density $\left(\mathrm{kg} \cdot \mathrm{m}^{-3}\right)$ \\
\hline$I$ & intensity $(A)$ & $\varphi$ & phase delay (rad) \\
\hline$k$ & thermal conductivity $\left(\mathrm{W} \cdot \mathrm{m}^{-1} \cdot \mathrm{K}^{-1}\right)$ & $\omega$ & angular pulsation $\omega=2 \pi f\left(\right.$ rad. $\left.^{-1}\right)$ \\
\hline$L$ & length $(m)$ & & \\
\hline$\dot{m}$ & mass flow rate $\left(\mathrm{kg} . \mathrm{s}^{-1}\right)$ & Subscripts & \\
\hline$N T U$ & number of heat transfer units $N T U=h S / \dot{m} c_{p}(-)$ & & \\
\hline$N u_{D_{h}}$ & Nusselt number $N u_{D_{h}}=h D_{h} / k_{(-)}$ & $a$ & alternating \\
\hline$P$ & heat flow rate $(\mathrm{W})$ & $c$ & continuous part \\
\hline$P e$ & Peclet number $P e=v D_{h} / a=\operatorname{Re} \operatorname{Pr}(-)$ & $e$ & wall thickness \\
\hline $\operatorname{Pr}$ & Prandtl number $\operatorname{Pr}=\mu c_{p} / k_{(-)}$ & $\exp$ & experimental \\
\hline$\dot{q}$ & heat flow rate by unit of volume $\left(\mathrm{W} . \mathrm{m}^{-3}\right)$ & $f$ & fluid \\
\hline$R$ & radius $(\mathrm{m})$ & $i$ & inside \\
\hline$R e_{D_{h}}$ & Reynolds number $R e_{D_{h}}=\rho v D_{h} / \mu(-)$ & in & inlet \\
\hline$r$ & radial coordinate $(\mathrm{m})$ & $m$ & mean \\
\hline$S$ & surface $\left(m^{2}\right)$ & $o$ & outside \\
\hline$T$ & temperature $(\mathrm{K})$ & out & outlet \\
\hline$T h$ & thickness (m) & $w$ & wall \\
\hline$t$ & time (s) & $\omega$ & excitation angular frequency \\
\hline$U$ & voltage (V) & $2 \omega$ & twice the excitation angular frequency \\
\hline
\end{tabular}




\section{Introduction}

Brazed aluminium heat exchangers are composed of flat tubes on the refrigerant side and louver fins on the air side. The flat tubes are grouped within a header, to use the heat exchanger in a parallel flow configuration. These exchangers have some advantages compared to the heat exchangers with round tube, such as charge reduction and higher heat transfer coefficient.

But, according to Hrnjak [1], reduced diameter implies a great number of parallel circuits. Conventional distributors are thus not suitable to small-channel heat exchangers. As a consequence, the refrigerant distribution is much more penalizing for these exchangers than for round tube heat exchangers. Indeed, according to Kulkarni et al. [2], an uneven distribution may result in a performance reduction up to $20 \%$.

Efficiency of heat transfer distribution is a direct consequence of refrigerant distribution at header inlet. Measurement of heat transfer coefficients would thus allow estimating the quality of this distribution. Infrared (IR) thermography is a reliable and non-intrusive technique for such measurements.

IR measurement of convective heat transfer usually involves steady state heating and the measurement of external temperatures used as boundary conditions to solve an inverse heat conduction problem. Transient techniques (single blow, impulse or periodic) are also efficient experimental methods to measure convective heat flux in transient conditions. The subject of the present study is the IR thermography methodology based on periodic temperature fluctuations to evaluate convective heat transfer coefficients.

Hausen [3] first developed this method, based on the measurement of phase shift and temperature amplitude. He applied this method to evaluate heat transfer coefficients on a regenerator.

Later, Roetzel et al. [4] applied a similar method, developed in Roetzel et al. [5], to characterize the transfer coefficients and dispersion in plate heat exchangers. Water was used as working fluid. A steady state method, already proven, was also applied for the sole purpose of comparison for the heat transfer measurement. Temperature oscillation was measured at the inlet and the outlet of the exchanger. The phase shift between these two temperatures and the ratio of the amplitude were used. A mathematical model relates the amplitude and the phase shift to the distribution of residence time in the exchanger and the heat transfer such that:

$$
\begin{aligned}
& \theta_{t h}(P e, N T U)-\theta_{\exp }=0 \\
& \varphi_{t h}(P e, N T U)-\varphi_{\exp }=0
\end{aligned}
$$

The results showed a good agreement between the two methods for low Reynolds numbers. However, for higher Reynolds numbers, the results obtained with the transient technique appeared to be higher than those obtained with the steady-state method. Two possible explanations for this difference were proposed. Firstly, for a high Reynolds number, the period used for the transient method was comparable with the time delay of pneumatic valves and the flow fluctuation effect. Secondly, the steady state method did not take dispersion into account.

Recently, Freund and Kabelac [6] developed a three-dimensional model which allows a rapid assessment of the distribution of heat transfer coefficients. The heat transfer coefficients are deduced from the phase shift between the heat source, usually a laser, and the temperature response of the wall. Freund et al. [7] and Freund and Kabelac [8] then applied this method to measure the distribution of convection coefficients on a plate cooled by jet impingement of air and on the surface of a plate heat exchanger. They obtained encouraging results, but specified that their model could not be transposed to more complex shapes than cylinders and plates.

As noted by Freund [9], heat transfer estimation requires an accurate measurement of the phase shift between heat flux and temperature response. This implies using hardware that enables the time gap between heat flux and temperature measurement to be precisely determined. Without such equipment and to avoid errors due to synchronisation of the device, temperature oscillation measurement is not sufficient to determine the heat transfer coefficient.

The present study focuses on the IR measurement of convective heat transfer coefficients in a horizontal pipe by temperature oscillations. The heating was generated here by Joule effect to maximize the accuracy of the measurement. The parameter considered for the estimation of the heat transfer coefficient was the temperature amplitude measured on the outside wall by infrared thermography.

The method was first applied to a round tube. A heat transfer model of the system was developed to correlate the heat transfer coefficient and the temperature amplitude. Considering the efficiency of the method for a round tube, it was then applied to a multiport flat tube. An analytical model was developed, and the results were compared to a resolution with the commercial software COMSOL and to theoretical values.

\section{Measurement principle}

The objective of measurement, performed in the GRESPI laboratory of Reims, was to estimate heat transfer coefficients between the flowing water and the inlet wall of a pipe. The two geometries have been studied, the round tube and the multiport flat tube. In both cases, the pipe was heated by Joule effect with a periodic excitation. The heat flux was measured with an ammeter and a voltmeter, and the oscillation of the outside surface temperature of the tube with 
an IR camera. Heat flux and temperature amplitude were used as entry variables in models to estimate heat transfer coefficients for a round tube and for a multiport flat tube.

Considering the temperature, the peak to peak amplitude of the oscillations varied from a few tenths of a degree to more than one degree of magnitude depending on the experimental conditions. For example, for the round tube, a power oscillating from $1.3 \mathrm{~W}$ to $11.0 \mathrm{~W}$ and a Reynolds number of 9200 induced a temperature amplitude of $0.35{ }^{\circ} \mathrm{C}$. A temperature amplitude of $1.17^{\circ} \mathrm{C}$ was reached with a power oscillating from $6.8 \mathrm{~W}$ to $18.0 \mathrm{~W}$ and a Reynolds number of 2500.

The tube was electrically heated by a sinusoidal wave DC generator which output voltage was modulated at low frequency $(f=0.05 \mathrm{~Hz}$ in this study). Since the tube acts as a pure resistance, the current is itself at the same frequency as the voltage and in phase with it.

$$
\begin{aligned}
& U=U_{m}+U_{a} \cos (\omega t) \\
& I=I_{m}+I_{a} \cos (\omega t)
\end{aligned}
$$

The power dissipated by Joule effect in the tube is equal to the product $U I$ and therefore has three components: a continuous one, one at the excitation frequency $\omega$ and one at a frequency twice that of the source. The model takes into account these components and is described for the two geometries, the flat tube and the round tube.

\section{Model developed for the round tube}

The relation between the periodic heating energy and the temperature oscillations for a round tube, as presented in Fig. 1, is composed of the heat conduction equation inside the tube wall and the boundary conditions. These conditions are in this case a convective heat flux imposed on the inner surface of the tube by the fluid flow and a condition of adiabaticity on the outer surface. Heat losses by external convection and radiation are negligible compared to the heat flux transferred to the fluid and will therefore be neglected. Considering the low power provided by the power supply, a second assumption is a constant fluid temperature. The third hypothesis concerns the independence of the thermodynamic properties of the material and of the convection coefficient with respect to the temperature. The fourth and last hypothesis is a $1 \mathrm{D}$ temperature variation. Angular and axial heat transfers are then neglected.

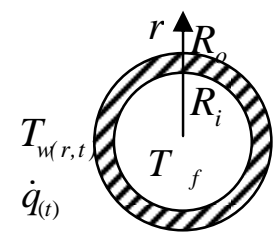

Fig. 1. Representation of the tube and related quantities

The following system of equations has to be solved twice, at the excitation frequency and at twice the excitation frequency. We will not solve the continuous system of equations which does not provide more information except for purposes of comparison. It includes the equation of energy conservation and the boundary conditions:

$$
\left\{\begin{array}{l}
\frac{\partial^{2} T_{w(r, t)}}{\partial r^{2}}+\frac{1}{r} \frac{\partial T_{w(r, t)}}{\partial r}-\frac{1}{a} \frac{\partial T_{w(r, t)}}{\partial t}=-\frac{\dot{q}_{(t)}}{k} \\
r=R_{i}-\left.k \frac{\partial T_{w(r, t)}}{\partial r}\right|_{r=R_{i}}=h\left(T_{f, i n}-T_{w\left(R_{i}, t\right)}\right) \\
r=R_{o}-\left.k \frac{\partial T_{w(r, t)}}{\partial r}\right|_{r=R_{o}}=0
\end{array}\right.
$$

Temperature, like power, has three components: a continuous one, one at the excitation frequency, and one at a frequency twice the excitation frequency. By defining:

$$
\theta_{(r, t)}=\left(T_{w(r, t)}-T_{f, i n}\right)
$$

And assuming a periodic established state, we have: 
$\theta_{(r, t)}=\theta_{c(r)}+\theta_{\omega(r)} \exp (j(\omega t+\varphi))+\theta_{2 \omega(r)} \exp (j(2 \omega t+\varphi))$

and:

$\dot{q}_{(t)}=\dot{q}_{c}+\dot{q}_{\omega} \exp (j \omega t)+\dot{q}_{2 \omega} \exp (j 2 \omega t)$

Where $\varphi$ is the phase shift between the temperature and the heat source. The resolution of the system provides the expression of $\theta_{\omega(r)} \exp (j \varphi)$ :

$$
\begin{aligned}
& \theta_{\omega(r)} \exp (j \varphi)=\frac{\dot{q}_{\omega}}{m_{\omega}^{2} k}+\frac{h \dot{q}_{\omega}}{m_{\omega}^{3} k^{2}}\left[K_{l}\left(m_{\omega} R_{o}\right) I_{0}\left(m_{\omega} r\right)+I_{l}\left(m_{\omega} R_{o}\right) K_{o}\left(m_{\omega} r\right)\right] / \\
& \left(I_{l}\left(m_{\omega} R_{o}\right)\left[-K_{l}\left(m_{\omega} R_{i}\right)-\frac{h}{m_{\omega} k} K_{0}\left(m_{\omega} R_{i}\right)\right]+K_{l}\left(m_{\omega} R_{o}\right)\left[I_{l}\left(m_{\omega} R_{i}\right)-\frac{h}{m_{\omega} k} I_{0}\left(m_{\omega} R_{i}\right)\right]\right)
\end{aligned}
$$

with:

$$
m_{\omega}=\sqrt{\frac{j \omega}{a}}
$$

In these equations $I_{0}, I_{1}$, and $K_{0}, K_{1}$ are the modified Bessel functions of the first and second kind respectively, of order zero and one. The same resolution was applied to the system at twice the excitation frequency to obtain $\theta_{2 \omega(r)} \exp (j \varphi)$. Knowing that:

$$
\theta_{(r)}=\left|\theta_{\omega(r)} \exp (j \varphi)+\theta_{2 \omega(r)} \exp (j \varphi)\right|
$$

an evaluation of the $h$ value is finally obtained by minimizing $\mathcal{E}$ such that:

$$
\mathcal{E}=\left|\theta_{\left(R_{o}\right) \exp }-\theta_{\left(R_{o}\right)}\right|
$$

where $\theta_{\left(R_{o}\right) \exp }$ is the experimental amplitude of the temperature oscillations. So, the knowledge of the properties of the tube material $c_{p}, k, \rho$, the excitation frequency $f$, the power densities $\dot{q}_{\omega}$ and $\dot{q}_{2 \omega}$ and the amplitude of the measured temperature $\theta_{\left(R_{o}\right) \exp }$ allow us to determine the convective heat transfer coefficient $h$.

\section{Models developed for the multiport flat tube}

Two models were developed for the multiport flat tube. An analytical 1-D model was first developed to allow sensitivity analysis. This first model was then compared to a 2-D resolution with the commercial software COMSOL.

\subsection{Assumption 1: Assimilation of the flat tube to a wall}

The first model developed considers the flat tube as a wall, as presented in Fig. 2. Thanks to the symmetry condition induced by the geometry, only half the flat tube was considered. The relation between the periodic heating energy and the temperature oscillations of the outside wall, as presented in Fig. 2, is composed of the heat conduction equation inside the wall and the boundary conditions. These conditions are a convective heat flux imposed on the inner surface of the tube by the fluid flow and a condition of adiabaticity on the outer surface. Indeed, heat losses by external convection and radiation are negligible compared to the heat flux transferred to the fluid and will be neglected. To take into account the influence of the fins formed by small-channel separations, two different surfaces were added to the model. Surfaces $s_{1}$ and $s_{2}$ were considered respectively for conduction and for convection. 


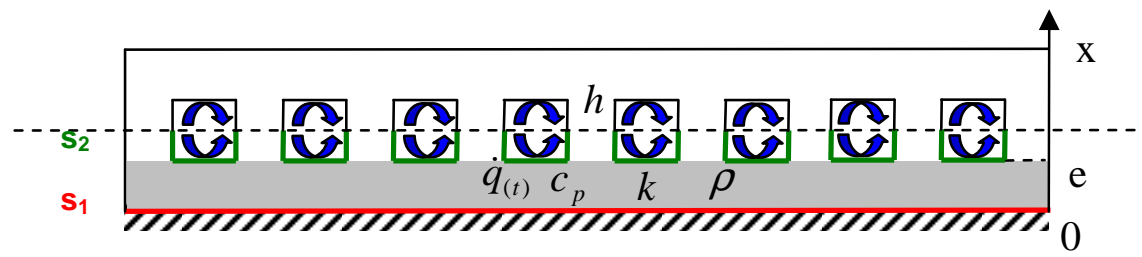

Fig. 2. Representation of the multiport flat tube and related quantities

As the heat flux provided is greater than the one delivered for the round tube, water temperature can't be considered constant. Indeed, as presented in Fig. 3, water temperature amplitude was not negligible compared to wall temperature amplitude. Water temperature was thus obtained through a power balance. Considering the low excitation frequency, the hypothesis was done that water phase shift was equal to tube phase shift. The third hypothesis concerns the independence of the thermodynamic properties of the material and of the convection coefficient to the temperature. The fourth and last hypothesis is a 1-D temperature variation. Heat transfers in any other direction than that of the $x$ axis are then neglected.

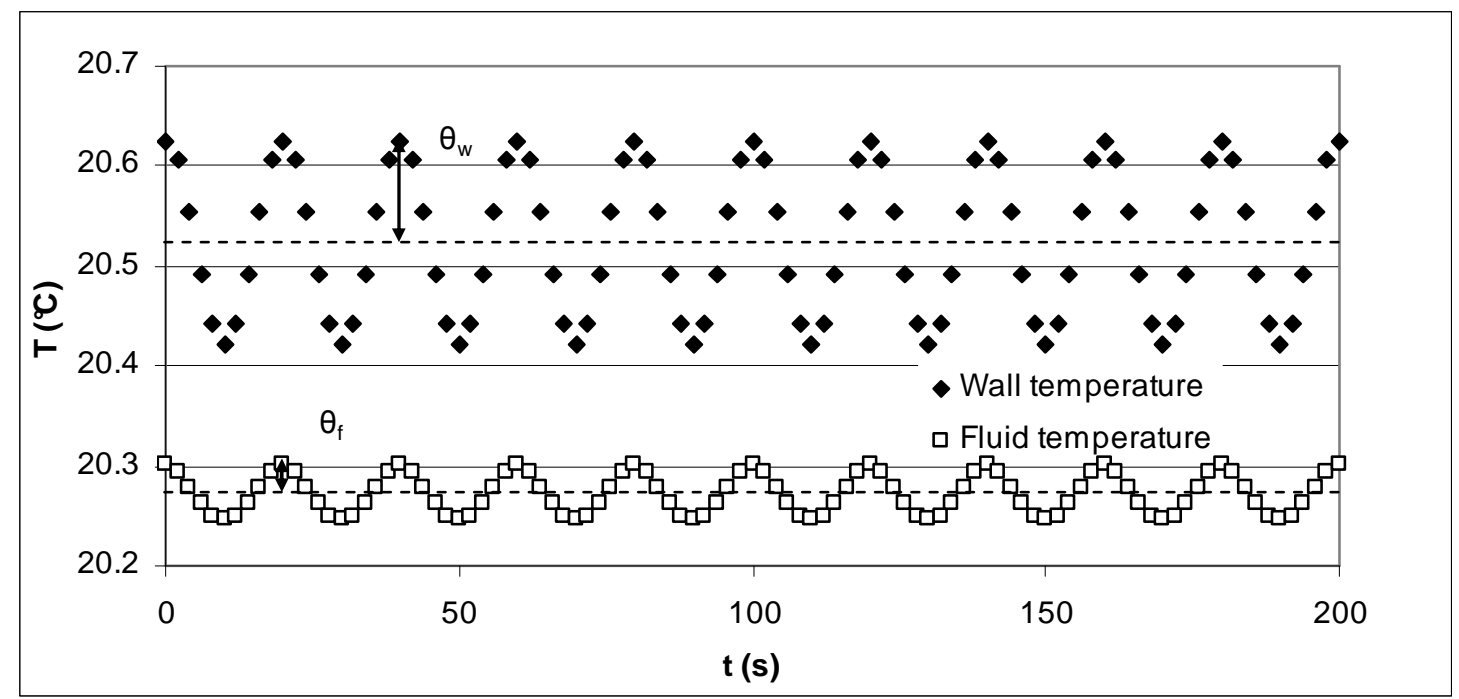

Fig. 3. Time evolution of wall and fluid temperature

The system to solve, composed of the energy equation and boundary conditions, is thus as follows:

$$
\left\{\begin{array}{l}
\frac{\partial^{2} T_{w(x, t)}}{\partial x^{2}}-\frac{1}{a} \frac{\partial T_{w(x, t)}}{\partial t}=-\frac{\dot{q}_{(t)}}{k} \\
x=e-\left.k s_{1} \frac{\partial T_{w(x, t)}}{\partial x}\right|_{x=e}=h s_{2}\left(T_{w(e, t)}-T_{f(t)}\right) \\
x=0-\left.k \frac{\partial T_{w(x, t)}}{\partial x}\right|_{x=0}=0
\end{array}\right.
$$

As for the tube, two systems must be resolved, one at the excitation frequency and the last at a frequency twice the excitation frequency. Considering Eq. (4) to (6), and with:

$$
\theta_{f(x, t)}=\left(T_{f(t)}-T_{f, i n}\right) \quad(12) \quad \text { and } \theta_{f(x, t)}=\theta_{f, c}+\theta_{f, \omega} \exp (j(\omega t+\varphi))+\theta_{f, 2 \omega} \exp (j(2 \omega t+\varphi))
$$

the power balance for water provides: 
$\theta_{f, \omega} \exp (j \varphi)=\frac{\dot{q}_{\omega} V}{\dot{m}_{f} c_{p, f}}$

the expression of $\theta_{w, \omega(r)} \exp (j \varphi)$ is:

$\theta_{w, \omega(x)} \exp (j \varphi)=\frac{\dot{q}_{\omega}}{m_{\omega}^{2} k}\left[1-\frac{\left(1-\frac{m_{\omega}^{2} k V}{\dot{m}_{f} c_{p, f}}\right) \operatorname{ch}\left(m_{\omega} x\right)}{\frac{k m_{\omega}}{h} \frac{s_{1}}{s_{2}} \operatorname{sh}\left(m_{\omega} e\right)+\operatorname{ch}\left(m_{\omega} e\right)}\right]$

(15) with $m_{\omega}=\sqrt{\frac{j \omega}{a}}$

The same resolution was applied to the system at twice the excitation frequency to obtain $\theta_{w, 2 \omega(r)} \exp (j \varphi)$. The resolution is then identical to the case of the cylinder.

\subsection{Assumption 2: COMSOL}

The problem was also solved with COMSOL. The geometry used for 2-D model is presented in Fig. 4, with 536 elements in the mesh. The boundaries noted 2 and 6 are considered insulated due to symmetry conditions. The boundary noted 1 is also considered insulated for the same reasons as previously, i.e. heat losses by external convection and radiation are negligible compared to the heat flux transferred to the fluid. An internal flux is also considered. The thermodynamic properties of the material and of the convection coefficient are considered independent with respect to the temperature.

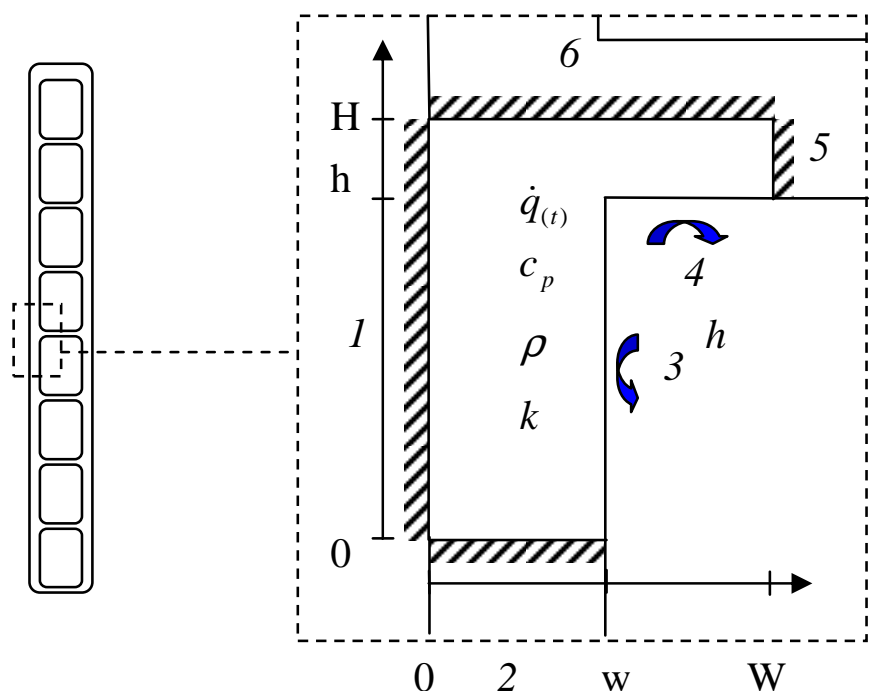

Fig. 4. Part of the multiport-flat tube considered for the COMSOL resolution

The following system of equations has to be solved, which includes the equation of energy conservation and the boundary conditions:

$$
\begin{cases}\nabla \cdot\left(\nabla T_{w(x, y, t)}\right)-\frac{1}{a} \frac{\partial T_{w(x, y, t)}}{\partial t}=-\frac{\dot{q}_{(t)}}{k} & \\ x=0-k \nabla T_{w(x, y, t)}=0 & y=0-k \nabla T_{w(x, y, t)}=0 \\ x=w-k \nabla T_{(x, y, t)}=h\left(T_{w(x, y, t)}-T_{f(t)}\right) & y=h \quad k \nabla T_{w(x, y, t)}=h\left(T_{w(x, y, t)}-T_{f(t)}\right) \\ x=W \quad-k \nabla T_{w(x, y, t)}=0 & y=H \quad-k \nabla T_{w(x, y, t)}=0\end{cases}
$$


The expression of the internal heat flux and the water temperature are as follow:

$\dot{q}_{(t)}=\frac{\left(U_{m}+U_{a} \cos (\omega t)\right)\left(I_{m}+I_{a} \cos (\omega t)\right)}{V}$

(18) $\quad T_{f(t)}=T_{f, i n}+\frac{\dot{q}_{\omega(t)} V}{\dot{m}_{f} c_{p, f}}$

The theoretical temperature amplitude is then calculated from temperature evolution provided by COMSOL. This value is then compared to the experimental value as for the second and third model up to obtain the value of the heat transfer coefficient.

\section{Experimental facility}

The tube in which the heat transfer coefficient measurements were carried out was connected to a hydraulic loop shown in Fig. 6. It was composed of a circulation pump and a water tank with a capacity of 100 I. Both tubes were arranged horizontally. The inner and outer diameters of the copper tube used were $6 \mathrm{~mm}$ and $8 \mathrm{~mm}$ respectively. The flat tube geometry is presented in Fig. 5. The water flow rate was controlled by a valve and provided Reynolds numbers ranging from 2000 to 14000 for the round tube, from 800 to 10000 for the flat tube. A thermocouple, located at the outlet of the tube, measured the water temperature during experiments in order to check that the water temperature remained constant during the test. The tank temperature was controlled using a thermocouple connected to the data logger.

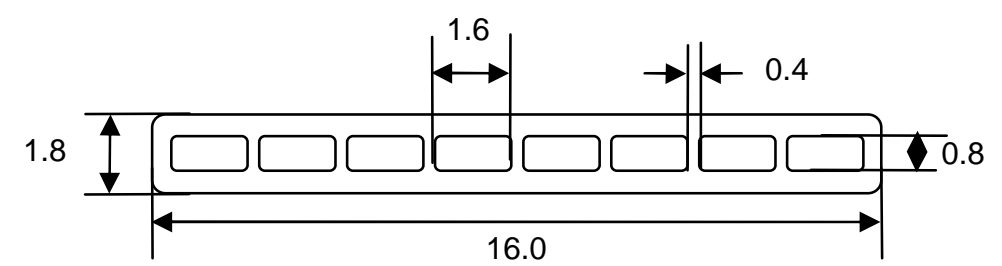

Fig. 5. Cross-sectional view of the multiport-flat tube (unit: $\mathrm{mm}$ )

To generate the periodic heat source and to monitor and measure the temperature oscillations, the experimental facility consisted in a power supply that delivers a periodic Joule effect heating and an infrared scanning device to monitor and measure the temperature of the tube surface, as shown on Fig. 6.

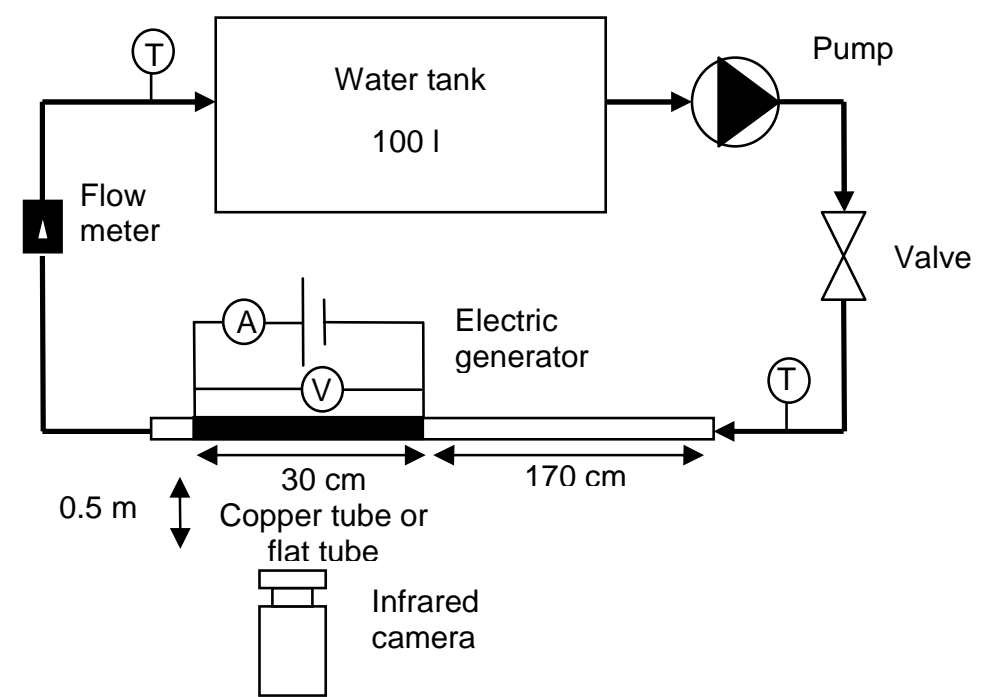

Fig. 6. Hydraulic circuit

In the test section for the round tube the studied area was located one meter from the flow entrance so that the requirement $L / D>40$, required to avoid entrance effect, is confirmed $(L / D=200)$. For the flat tube, which test section is presented in Fig. 7(a), the length of the tube did not allow satisfying this condition. Indeed, the total length of the flat tube, including the transition from flat to round tube, is of $65 \mathrm{~cm}$. The flow pattern was not established at the measurement point.

For both cases, length of $30 \mathrm{~cm}$ was heated by Joule effect at a frequency of $0.05 \mathrm{~Hz}$. This effect was located between two electrodes connected to the power supply with copper cables. A clamp ammeter and a voltmeter were connected to the data logger to measure electric current in the tube and voltage between the two electrodes over time. 
The thermographic camera (Titanium Cedip) measured the temperature on the external surface of the tube at a frequency of $2 \mathrm{~Hz}$. This allowed the capture of 400 points in 200 seconds and thus 10 periods. The external surface of the two tubes was painted in black in order to increase and homogenize their emissivity. The area observed by the camera was about $10 \mathrm{~cm}$ long and was located in the middle of the area heated by Joule effect. The area considered for calculation, presented in Fig. 7(b), is a part of the tube that is about $0.5 \mathrm{~cm}$ wide and $1 \mathrm{~cm}$ high.

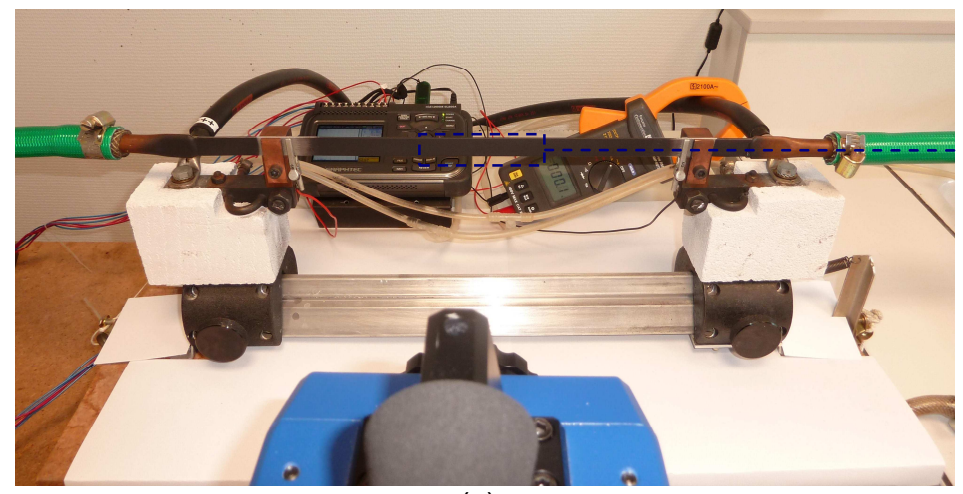

(a)

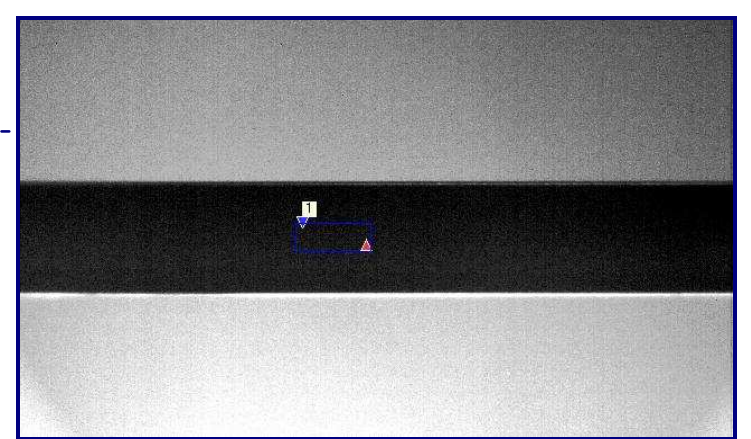

(b)

Fig. 7. Test section (a) and area considered (b)

\section{Experimental results}

The experiments were conducted for a large range of water flow rates. The results obtained experimentally were compared with values obtained from three empirical correlations. For each one, thermodynamic properties were considered at mean temperature, such that:

$$
T_{m}=\left(T_{\text {in }}+T_{\text {out }}\right) / 2
$$

The correlation of Gnielinski [10], adapted to transitional and turbulent flows is given by:

$$
N u_{D_{h}}=\frac{\Lambda / 8\left(\operatorname{Re}_{D_{h}}-1000\right) \operatorname{Pr}}{1+12.7 \sqrt{\Lambda / 8}\left(\operatorname{Pr}^{2 / 3}-1\right)}\left[1+\left(D_{h} / L\right)^{2 / 3}\right]\left(\operatorname{Pr} / \operatorname{Pr}_{w}\right)^{0.11}
$$

with $L$ the length of establishment of the flow in the tube before the measurement point, $P r_{w}$ the value of the Prandtl number at wall temperature and $\Lambda$ the Darcy friction factor defined by:

$$
\Lambda=0.3164 / \operatorname{Re}_{D_{h}}^{1 / 4}
$$

This correlation is valid for $1.5<\operatorname{Pr}<500,2300<\operatorname{Re}_{D_{h}}<10^{6}$ and $0<D / L<1$.

The correlation of Hausen (Kakac et al. [11]), also used for comparison and valid for transitional and turbulent flows, is defined by:

$$
N u_{D_{h}}=0.116\left(\operatorname{Re}_{D_{h}}^{2 / 3}-125\right) \operatorname{Pr}^{1 / 3}\left(\mu\left(T_{m}\right) / \mu\left(T_{w}\right)\right)^{0.14}\left[1+\left(D_{h} / L\right)^{2 / 3}\right]
$$

with $T_{m}$ and $T_{w}$ corresponding to the average temperatures of the fluid and the tube. This correlation is valid for $2300<R e_{D_{h}}<10^{4}$.

The experimental results were also compared to values obtained from the correlation of Colburn [12] :

$$
N u_{D_{h}}=0.023 \operatorname{Re}_{D_{h}}^{0.8} \operatorname{Pr}^{1 / 3}
$$

This correlation is valid for $0.7<\operatorname{Pr}<120,10^{4}<\operatorname{Re}_{D_{h}}<1.210^{5}$ and $L / D>60$. The thermodynamic properties were considered at film temperature, which is the mean between $T_{w}$ and $T_{m}$. 
For laminar flow, the correlation of Edwards et al. [13] was used:

$N u_{D_{h}}=3.66+\frac{0.065\left(D_{h} / L\right) R e_{D_{h}} \operatorname{Pr}}{1+0.04\left[\left(D_{h} / L\right) R e_{D_{h}} \operatorname{Pr}\right]^{2 / 3}}$

This correlation was developed for developing laminar flow in the entrance region with constant surface temperature.

The results obtained for the round tube are presented in Fig. 8. These results show good agreement between experimental and theoretical results. Results are close to those obtained with the Gnielinski [10] correlation for a Reynolds number lower than 10000. Despite the fact that the correlation of Gnielinski is available for a wide range of values, it appears that experimental results are more consistent with the values obtained with the Colburn [12] correlation for greater values of Reynolds number. The correlation of Gnielinski [10] is indeed proposed with $20 \%$ of error.

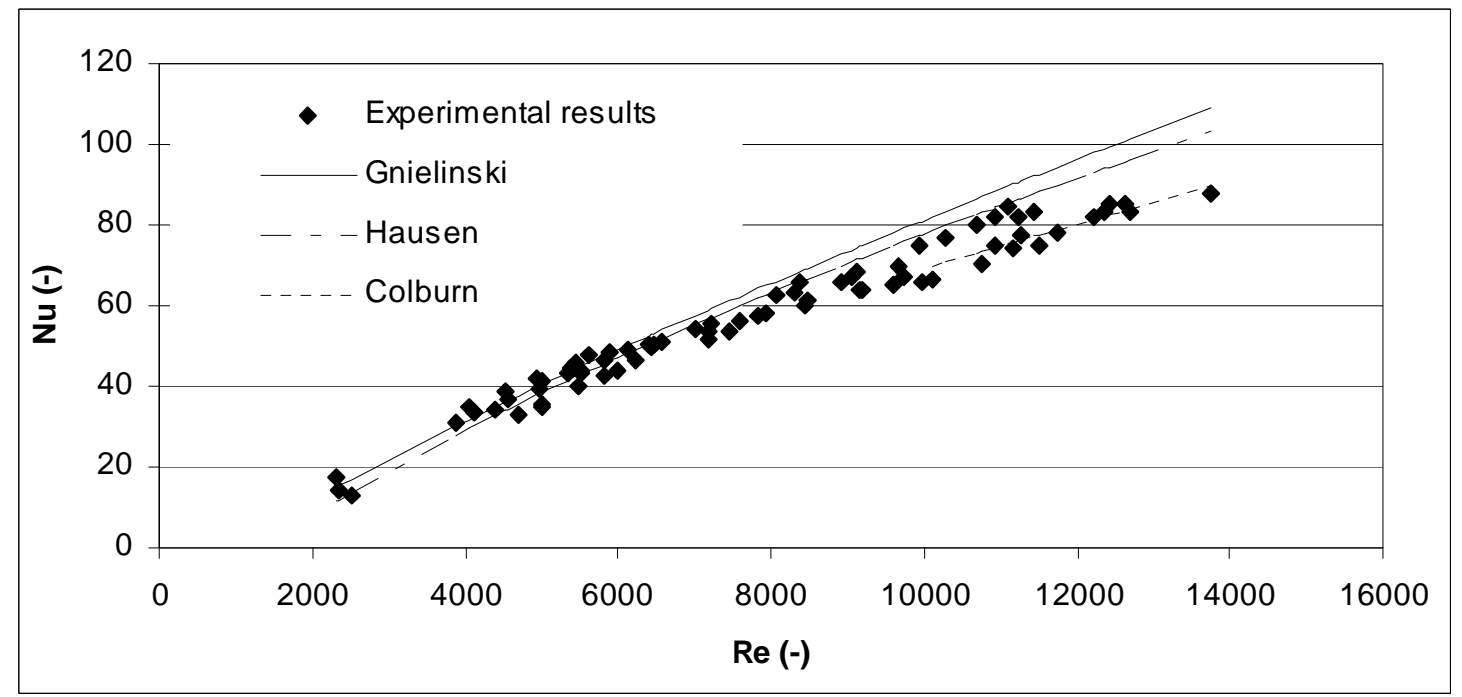

Fig. 8. Comparison of Nusselt numbers obtained experimentally and from correlations as a function of the Reynolds number for the round tube

These results highlight the efficiency of the method for a configuration widely studied in the literature. Considering multiport flat tube, results are presented in Fig. 9. First of all, the two models provide similar results. Concerning the shape, it appears that flow patterns observed are consistent with theory. Transition between laminar and turbulent begins for a Reynolds number of almost 2000, as predicted by literature. Finally, the two curves, theoretical and experimental, have the same trends.

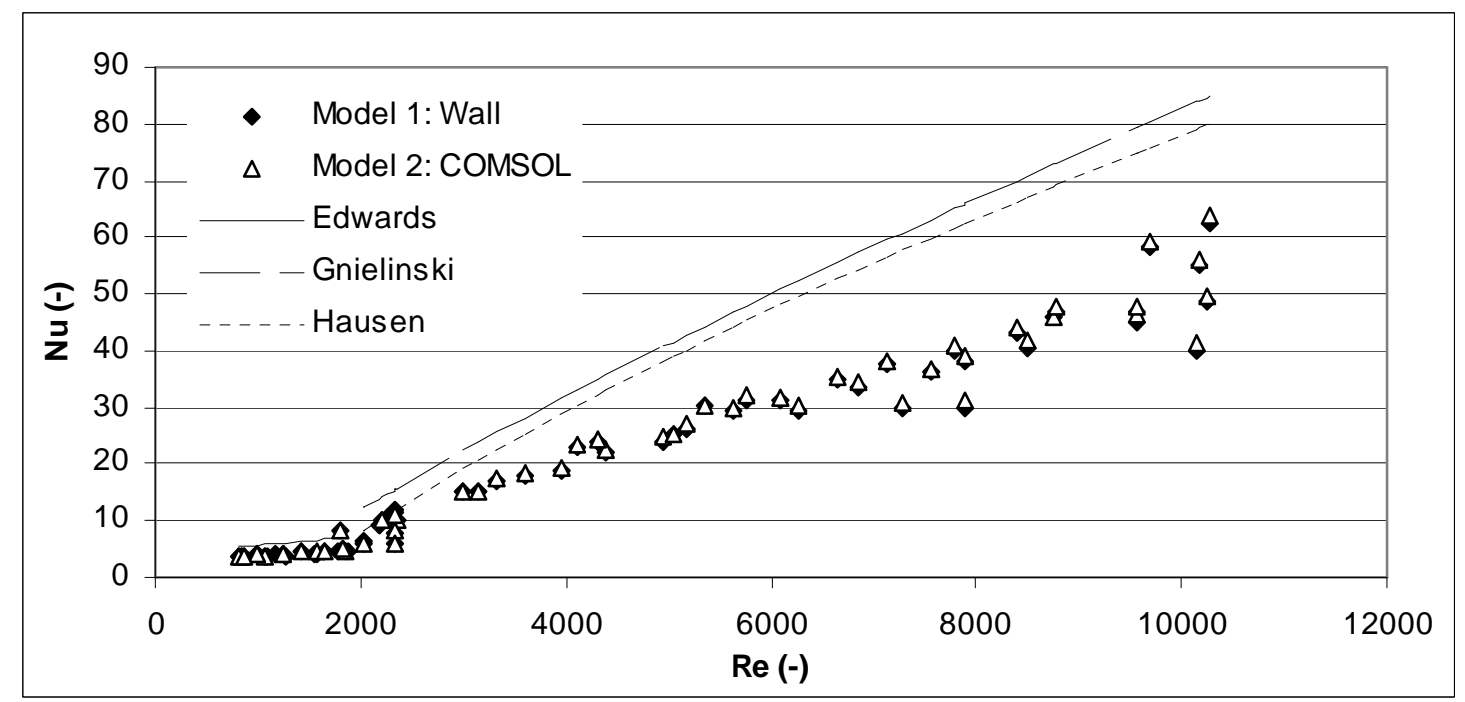

Fig. 9. Comparison of Nusselt numbers obtained experimentally and from correlations as a function of the Reynolds number for the multiport flat tube 
Values obtained experimentally appear lower than those obtained with correlations. This difference can be linked to the geometry. Indeed, correlations were established for round tubes, whereas small-channels are rectangular. Moreover, discrepancies observed for high Reynolds numbers highlight the necessity of increasing heat flux to obtain a better precision for high heat transfer coefficients.

\section{Conclusion}

A method has been developed to measure the convective heat transfer coefficient in a tube. This method is based on a modulated heat flux generated by Joule effect. In this way, the measurement of the amplitude of the tube outside wall temperature with an infrared thermographic camera allows internal heat transfer coefficients to be determined through a simple analytical model or by using commercial software. The simplicity of the model allows appliance to more complex shaped tubes. This flexibility makes it a perfect tool for controlling series of elements with a similar shape.

This method has the advantage of being non intrusive. It enables heat transfer differences to be estimated without requiring knowledge of the flow rate, temperature or properties of the fluid. Moreover, it does not require a high heat flux, thus avoiding strong perturbation of the fluid properties.

The use of infrared thermography will allow us measuring heat transfer simultaneously on several tubes connected in parallel. Another insight is to apply lock-in thermography. By this mean, we will have two series of data, phase map and amplitude map, to deduce heat transfer coefficient map.

\section{Acknowledgements}

This work has been supported by the Cetim foundation as part of the research project "Two Phase Flow Distribution in a Compact Heat Exchanger".

\section{REFERENCES}

[1] Hrnjak, P., "Microchannel heat exchangers as a design option for charge reduction in NH3 and HC systems". Zero Leakage - Minimum Charge, 2002: p. 111-118.

[2] Kulkarni, T., C.W. Bullard, and K. Cho, "Header design tradeoffs in microchannel evaporators". Applied Thermal Engineering, 2004. 24(5-6): p. 759-776.

[3] Hausen, H., "Wärmeübertragung im Gegenstrom, Gleichstrom und Kreuzstrom, 2nd Ed." 1976, Berlin: Springer Verlag.

[4] Roetzel, W., S.K. Das, and X. Luo, "Measurement of the heat transfer coefficient in plate heat exchangers using a temperature oscillation technique". International Journal of Heat and Mass Transfer, 1994. 37(SUPPL. 1): p. 325-331.

[5] Roetzel, W., X. Luo, and Y. Xuan, "Measurement of heat transfer coefficient and axial dispersion coefficient using temperature oscillations". Experimental Thermal and Fluid Science, 1993. 7(4): p. 345-353.

[6] Freund, S. and S. Kabelac. "Measurement of local convective heat transfer coefficients with temperature oscillation IR Thermography and radiant heating". in Proceedings of the ASME Summer Heat Transfer Conference. 2005. San Francisco, CA.

[7] Freund, S., A.G. Pautsch, T.A. Shedd, and S. Kabelac, "Local heat transfer coefficients in spray cooling systems measured with temperature oscillation IR thermography". International Journal of Heat and Mass Transfer, 2007. 50(9-10): p. 1953-1962.

[8] Freund, S. and S. Kabelac, "Investigation of local heat transfer coefficients in plate heat exchangers with temperature oscillation IR thermography and CFD". International Journal of Heat and Mass Transfer, 2010. 53(19-20): p. 3764-3781.

[9] Freund, S., "Local Heat Transfer Coefficients Measured with Temperature Oscillation IR Thermography", in "Thermodynamics". 2008, Helmut-Shmidt-University: Hamburg. p. 142.

[10] Gnielinski, V., "New Equations for Heat and Mass-Transfer in Turbulent Pipe and Channel Flow". International Chemical Engineering, 1976. 16(2): p. 359-368.

[11] Kakac, S., R.K. Shah, and W. Aung, "Handbook of Single-Phase Convective Heat Transfer". 1987, New York: John Wiley and Sons

[12] Colburn, A.P., "A method of correlating forced convection heat transfer data and a comparison with fluid friction". Trans. AIChE, 1933. 29: p. 174-210.

[13] Edwards, D.K., V.E. Denny, and A.F. Mills, "Transfer Processes". 2nd ed. Washington, DC: Hemisphere, 1979. 